\title{
Knowledge Mobilization for Enhanced Organization Performance of Firms Listed in the Nairobi Securities Exchange
}

\author{
Lore Ambrose Ekunoit ${ }^{1}$, Erastus Thoronjo ${ }^{2}$ \\ ${ }^{1}$ Mount Kenya University, Thika, Kenya \\ ${ }^{2}$ School of Business and Economics, Mount Kenya University, Thika, Kenya \\ Email: ceale07@yahoo.com
}

How to cite this paper: Ekunoit, L. A., \& Thoronjo, E. (2021). Knowledge Mobilization for Enhanced Organization Performance of Firms Listed in the Nairobi Securities Exchange. Open Journal of Business and Management, 9, 3011-3025.

https://doi.org/10.4236/ojbm.2021.96168

Received: September 28, 2021

Accepted: November 22, 2021

Published: November 25, 2021

Copyright $\odot 2021$ by author(s) and Scientific Research Publishing Inc. This work is licensed under the Creative Commons Attribution International License (CC BY 4.0).

http://creativecommons.org/licenses/by/4.0/

\begin{abstract}
Many companies trading in the NSE had been reporting reduced financial performance in the period between 2014-2019. This scenario brings to the fore the significant role that knowledge mobilization plays in influencing performance of these organizations. This research study was meant to explore how knowledge mobilization influences how firms listed in the NSE perform. It was anchored on resource-based theory. The study applied a descriptive research design and the study was conducted in Nairobi. The population studied was 36 trading companies in the different categories of the NSE. The study did not apply any sampling technique since the study population was small and manageable. A questionnaire was the research tool. Pilot testing was conducted to assess the reliability and validity of the research instrument. The drop-off/pick-up method of administration was employed. Inferential and descriptive means were used to analyze the data. Specifically, analysis by regression was used to find out whether knowledge mobilization played any role on performance of the listed companies. The study findings established that knowledge mobilization had a positive and significant effect on organizational performance of firms listed in the NSE $(\beta=1.007 ; p<.05)$. The following recommendations are provided. First, it is recommended that the NSE listed firms should adopt an organizational structure that supports knowledge creation and sharing, instill leadership that supports a knowledge culture, and provide incentives and reward systems for knowledge creation and sharing.
\end{abstract}

\section{Keywords}

Knowledge Mobilization, Organization Performance, Listed Firms, Nairobi Securities Exchange 


\section{Introduction}

According to Davis and Simpson (2017), resources consist of all information, assets, firm characteristics, competencies, organizational procedure as well as knowledge possessed within a company that enables formulation and execution of plans that affect its effectiveness and efficiency. In this globalization era, companies are continually engaging in knowledge mobilization to enable them to establish and meet market needs (Teece, 2016). Most companies are majorly focused on enhancing their capacity to increase customer numbers, grow revenues, asset bases and profitability. Wheelen and Hunger (2010) observe that firms in all sectors are engaged in continuous development focused on increasing sales and making investments in human, technological and material resources to benefit from the experience curve and reduce the expense of services or product offered. Okumu, Olweny and Muturi (2021) observe that firms globally are focused on enhancing their efficiency and innovation to guarantee that the costs of services end up being progressively affordable.

In Nigeria, Palladan, Abdulkadir et al. (2016) indicate that firms use knowledge mobilization to enhance their performance. Palladan et al. (2016) note that when an organization has some knowledge resources in place coupled with strategic leadership, they can enhance their long-term performance, develop and maintain organizational performance. This relates to insights from a survey of 17 African countries by Davis and Simpson (2017). Employee knowledge and leadership resources were indicated as key strategic resources that companies in these countries use to attain and maintain high performance (Davis \& Simpson, 2017).

In Ghana, small and medium enterprises (SMEs) utilize strategic resources such as knowledge mobilization to remain competitive in the marketplace. In Uganda, Malika and Kilika (2014) observe that firms in the telecommunication sector use knowledge management, innovation, employee competence and management efficiency to create and maintain organizational performance. These firms have created systems for continually enhancing the capacity of employees. Moreover, these firms have a system for leadership development that ensures the organization has adequate and effective leaders at all times.

Locally, a study conducted by Letangule and Letting (2012) on the telecommunications sector investigated the influence that knowledge management and innovation has on company's performance. It was established that knowledge management and innovation contribute to enhanced performance of firms in the sector. Further, Malika and Kilika (2014) established that leadership and organizational entrepreneurship are key factors that enable organizations to sustain high performance and remain competitive. The firms under study were in the manufacturing sector. The current study sought to study sample of firms trading in institutions drawn across different sectors. The findings would be generalized to various sectors since NSE has firms from all sectors. 


\subsection{The Nairobi Securities Exchange (NSE)}

From its inception in 1954 (NSE, 2019a) to date, NSE has undergone various changes including registration as a limited liability company in 1991, increased registration from stockbrokers necessitated the split of the market into three segments; segment for the fixed income securities, segment for alternate investment and segment for main investment in 2001. Other key NSE milestones include automation of trading in 2004, introduction of live trading in 2006 and introduction of remote trading in 2007 among others that later led to its transformation to Nairobi Security Exchange in 2011. In 2013, NSE introduced the Growth Enterprises Market Segment (GEMS) for SMEs. In 2014, NSE demutualized and was listed (NSE, 2019b).

NSE was formed as a voluntary alliance of stockbrokers. Its role was to regulate trading activities and develop the securities market. It lists debt and equity and provides a trading platform to enable effective trading of these capital and money market securities by both international and local investors (NSE, 2019a). NSE is significant in financial deepening as well as country's economic growth by encouraging investments and savings. It also enables companies, both local and international, to access capital for growth and expansion. It also provides liquidity to investors by establishing a liquid market for the capital securities.

The Capital Markets Authority (CMA) of Kenya oversees operations of NSE. The NSE consists of 66 listed firms in different categories. These categories include investments, manufacturing, commercial and services and real estate. Others include energy and petroleum, telecommunications, construction, agricultural and banking. NSE also includes firms in insurance and investment sectors (NSE, 2019c). This study focused on 36 firms selected from the 12 categories in the NSE.

\subsection{Statement of the Problem}

Several listed firms in the NSE have been struggling to maintain and improve their financial performance with most posting deteriorating financial results. While some companies are posting huge profits, others are performing at their worst posting losses. Some of the listed firms posting poor financial results include National Bank of Kenya, Kenya Airways, East African Portland Cement, and Eveready East Africa among others (NSE, 2019c). Kenya Airways made a loss of KES 13 billion in 2019 while Eveready East Africa made a loss of 72.6 million in 2019 (NSE, 2019a). The poor performance by some of the NSE listed firms bring to the fore the important role that knowledge mobilization and alignment plays in influencing the performance of organizations.

Studies have been conducted globally, regionally and locally on the influence that knowledge mobilization have on companies' financial performance. For example, a study done by Othman et al. (2015) in Malaysia established that knowledge mobilization was a key factor in enhancing firm performance. However, Malaysia where the study was conducted has key differences with the Kenyan 
context. According to Lin and Tsai (2016), despite shared resources, the performance of firms differs greatly based on internal strategic resources. Local studies such as Malika and Kilika (2014) established that leadership and knowledge mobilization are key factors in firm financial performance. However, this study did not focus on all the sectors of the NSE. This study was therefore meant to address the existing gaps through assessing influence of knowledge mobilization on performance of companies listed in the NSE.

\subsection{Purpose of the Study}

This study was meant to demonstrate influence of knowledge mobilization on performance of firms trading in the NSE. The specific objective of the study is hence to understand the influence of knowledge mobilization on performance of firms trading in the NSE.

\section{Literature Review}

This part is important as it highlights the review of empirical studies as well as theoretical review of literature which the study is anchored on. It also presents the conceptual framework that illustrates hypothesized association between the study variables. It provides an analysis of past studies on knowledge mobilization and organizational performance.

\subsection{Theoretical Literature}

This study was based on the resource-based theory (RBT) by Wernerfelt (1984) which indicates that an organization should focus on the internal resources to establish organizational performance rather than concentrating on the external environment. Barney (1991) supports the theory and explains how it emphasizes on the application of the distinctive resources (firm and competencies) in formulation and execution of strategy. However, a key concern for RBT is the transitory nature of organizational resources and how they enable the firm to gain organizational performance. Atoche (2017) posits that the skills, knowledge, capacities and resources in the employees of the organization is the source of sustainable organizational performance for the firm. Further, Bowman and Ambrosini (2013) support this view by observing that leaders in the organization should seek to mobilize, acquire, build, transform, shape and combine the employee capacities into strategic resources that facilitate the organization to realize organizational performance. One of the key capacities in employees is knowledge.

Knowledge is considered as essential resource that serves as a guiding framework in the strategic management process in the organization. This theoretical approach is relevant for this study to explain how knowledge mobilization can facilitate the organization to realize organizational performance. Talaja, Miočević and Alfirević (2017) hypothesized that knowledge in employees enables a firm to be more responsiveness to the changing competitive, market and customer dy- 
namics. Knowledge therefore qualifies to be a strategic resource that enables the firm to create new products and improve existing offerings as dictated by the market changes. This facilitates the organization to continue in satisfying market expectations. Therefore, knowledge is a key antecedent of the firm's competitive position. Various authors such as Kumar, Jones et al. (2011), and others have used the RBV theory in their studies on the linkage between organizational knowledge and organizational performance. As this section lays the theoretical basis for the study, the next section provides the empirical studies conducted on the study area.

\subsection{Empirical Studies on Knowledge Mobilization and Organizational Performance}

In a study in Malaysia, Ismail, Rose, Uli and Abdullah (2017) investigated the association between organizational performance and organizational learning. The study focused on all Malaysian manufacturing companies and randomly selected 1000 manufacturing companies. The study was cross-sectional where data gathering was done using a questionnaire while multiple linear regression employed for data analysis. Study findings indicated that organizational learning was critical in influencing organizational performance. Important aspects in organizational learning were knowledge creation, knowledge transfer and knowledge retention.

Farrukh and Waheed (2015) conducted a meta-analytical study on 26 scientific studies to find out the relationship between learning in an organization and performance. The study established that organizational learning enables organizations to develop, manage and enhance processes, systems, standards and knowledge that enable the firm to adjust to the sudden shift in its external environment and improve their effectiveness and efficiency. These improvements enable the firm to effectively utilize its financial, intellectual and human resources to produce valuable output. The learning resource of the organization is critical for today's organization as they operate in a complex and dynamic environment which undergo constant changes. To gain advantage over their rivals, organizations have turned to organizational learning to enhance their adaptability to the changing market conditions.

On a study in Croatia, Klindžić and Galetić (2015) explored the influence of organizational learning on organizational performance. The authors recognized that the tumultuous nature of organizational ecosystem and the elaborate landscape of globalization trends are placing firms in circumstances which require their proactivity and adaptability. Such proactive capacity and adaptability are firmly linked to the learning capacity of the firm. Learning enables the firm to enhance its capacity to act in response to various business settings and thus generating new knowledge that enhances their organizational performance. Consequently, firms must control their organizational learning competencies successfully to produce above average performance and organizational perfor- 
mance.

Shahram Gilaninia et al. (2013) interrogated the association organizational performance and organizational learning. This research used a causal design that emphasized on the using analytical and descriptive techniques. The data was collected through a questionnaire survey. The target was 589 SMEs in Guilan province, Iran. A sample of 236 enterprises were selected using convenience non-probability sampling technique. Data analysis was through structural equation modelling using the LISREL software. The study findings showed that organization learning has relationship with organizational performance though development of strategic flexibility and cost leadership strategy.

\subsection{Conceptual Framework}

Figure 1 shows the conceptual framework which guided the study. In the framework, the study hypothesizes that knowledge mobilization is the independent variable while organizational performance is the dependent variable. Knowledge mobilization is hypothesized to influence the organizational performance of the firm.

\subsubsection{Knowledge Mobilization}

Knowledge mobilization refers to the process where new insights and knowledge are gained from the shared experiences of organizational members to significantly impact job behaviours and improve firms' resources (Klindžić \& Galetić, 2015). According to Farrukh and Waheed (2015), knowledge mobilization generates organizational knowledge which in then reflected in formal cultural models, information databases, shared mental models, formalized routines and procedures and theories in use which guide work performance. Knowledge mobilization enables acquisition, generation, sharing and retention of knowhow. This leads to generation of expertise and experience that facilitate organizational performance in the firm. In this study, knowledge mobilization was measured through practices in knowledge acquisition, knowledge generation, knowledge sharing and knowledge retention.

\subsubsection{Organizational Performance}

An organization attains organizational performance when it uses its available resources and resources to achieve success which is above the average experienced by other firms in the sector. Organizational performance enhances firm's growth, attain high market share, discourage entry to the industry and achieve

\section{Independent variable}

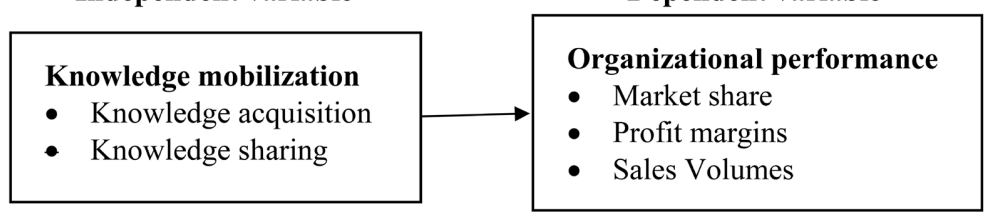

Figure 1. Conceptual framework. 
sustained above average profitability. Organizational performance can be measured using potential competitiveness indicators or past performance indicators. Ismail et al. (2017) indicated that key measures can include productivity, market share, gross margin, product cost, net income, returns on assets and unit cost ratio. Moreover, Malika and Kilika (2014) noted that financial performance (returns on investment, growth in sales, profit), total factor productivity, and nonfinancial performance (Employee's growth, Job satisfaction of employee and customers) are robust indicators of organizational performance. In this study, organizational performance was gauged through sustained high financial performance, market share and customer satisfaction.

\section{Research Methodology}

\subsection{Research Design}

This study used a descriptive research design. Thomas (2016) describes descriptive research as one that provides characteristics of a population and the association between study variables without interfering in the environment. This type of design was suitable because the study was meant to describe how strategic resources are mobilized in NSE listed firms and how that influences their financial performance. The study was done in Nairobi since all the NSE listed firms had offices in Nairobi. Information was gathered from 36 listed companies drawn from each of the 12 categories of firms listed in the NSE. Three firms were randomly selected from each category. These categories included investments, manufacturing, commercial and services and real estate. Others include energy and petroleum, telecommunications, construction, agricultural and banking. NSE also includes firms in insurance and investment sectors (NSE, 2019c). The Strategy directors in the targeted firms were the target respondents. No sampling technique was applied on the study because the study population was small According to Kurpius and Stafford (2016), sampling is only appropriate when dealing with large populations.

\subsection{Data Collection}

Questionnaire was used as the research tool. Gillham (2018) points that a questionnaire provides several advantages over other methods of data collection. The questionnaire had three segments. The first part sought general information about respondents, while the second section contained questions relating to knowledge mobilization. The last segment had questions on financial performance. The questionnaire had closed questions (5-point Likert scale type questions). One of the key questions was "Whether the organization has a collective information collection, sharing and storage system". These questions were used because more powerful statistical analysis can be utilized to analyse the collected data (Kothari, 2004). Any secondary information was recorded in the last part of the questionnaire. This was data on profitability and market share. 
The draft questionnaire was pilot tested with four employees from the directorate of planning in the State Department of Petroleum and Mining. This was $10 \%$ of the study sample (Kurpius \& Stafford, 2016). The pilot test was done to ensure that the questionnaire was suitable for data collection. The pilot test established whether there were any changes required on the design of the study or the questionnaire. The questionnaire was also tested for validity and reliability. Content and face validity of the questionnaire were tested through expert reviews, triangulation, and through results of pilot test. The questionnaire was also tested on reliability by the use of Cronbach's alpha and the scales were found to be reliable (Cronbach's alpha coefficient of over 7).

Collection of data commenced after designing of the final questionnaire and approval. The first step was to seek permission from the companies and all relevant authorities. The second step was seeking for the study respondents in every organization. After establishing the study respondents, questionnaires were administered to the respondents at their work places. Drop and pick method of administration was used. The researcher ensured that participants were reminded to ensure that they responded to the questionnaires. This was done using phone calls, e-mails or follow-up visits to the participants. This was done to ensure that there was a good response rate. In the whole research process, ethical Considerations Related to Researcher and those Concerning Participants were observed. Published financial reports of participating firms were used as the secondary data as well as data for the latest financial year on market share and profitability to assess their financial performance.

\subsection{Data Analysis}

Data analysis process began after collecting the filled questionnaires from participants from the 36 companies. This involved scrutinizing, cleaning, coding and transforming data into useful information (Babbie, 2011). After inspecting the questionnaires, coding followed which entailed keying the responses into software. Statistical Package for Social Sciences (SPSS) software version 24 was used in analysing the research data. Analysis of data was through inferential and descriptive statistics. Inferential statistics were used to facilitate answering of the research questions. Specifically, regression analysis was used to find out whether knowledge mobilization had a significant influence on financial performance of the companies.

The regression model used was;

$$
Y=\beta_{0}+\beta_{1} X_{1}+\varepsilon
$$

where, $Y=$ Organizational Performance,

$\beta_{0}=$ Constant

$\beta_{1}=$ Regression coefficient,

$X_{1}=$ Knowledge Mobilization,

$\varepsilon=$ Error term. 
Descriptive statistics such as frequency distributions, percentages, means and standard deviations provide a central tendency, dispersion and distribution of the responses regarding strategic capabilities and competitive advantage. This enabled the study to establish the prevalence of knowledge mobilization in the companies. The results of the analysis were presented in tables. This was then interpreted and discussed based on the theoretical and empirical literature.

\section{Results and Discussion}

\subsection{Introduction}

This section presents the results and their discussion. The study targeted 36 potential respondents from 36 firms listed in the NSE. All the respondents filled and submitted the administered questionnaires which translated to a response rate of $100 \%$. This was achieved because the sample was small and manageable within the time and resources at the disposal of the researcher. Besides, the study engaged in intense follow through phone calls, e-mail and personal visits. On level of management of respondents, study results indicated that $63.9 \%$ of the respondents were in middle management while $36.1 \%$ of the respondents were in top management. There were no lower management or non-management respondents. These findings suggest that the study targeted the right respondents who could provide the required information on strategic resources mobilization and financial performance in the selected firms listed in the NSE.

\subsection{Knowledge Mobilization}

Knowledge mobilization was the independent variable that was predicted in the study to have an effect on organizational performance of the firms listed in the NSE. This section provides descriptive analysis results regarding knowledge mobilization in the surveyed NSE listed firms in Kenya. Respondents were provided with 7 statements on knowledge mobilization and were requested to rate the statements in the context of the nature of knowledge mobilization within their organizations. They were requested to rate the statements on a scale of $1-5$ (Strongly disagree $-\mathrm{SD}$, disagree-D, Neutral $-\mathrm{N}$, agree $-\mathrm{A}$, and strongly agreeSA). This section provides descriptive statistics from the analysis of the Likert scale responses. Means scores, standard deviations and percentages were derived from the analysis and findings are presented in Table 1.

The findings displayed in Table 1 show that $50 \%$ of the study respondents strongly agreed that their organizations had a formal knowledge sharing policy while $44.4 \%$ also strongly agreed that their organizations had adequate equipment and resources to gather knowledge. Moreover, $44.4 \%$ agreed that management ensures that new knowledge and information is disseminated to all relevant organization employees. Besides, $41.7 \%$ strongly agreed that resources and time for learning is readily available to employees in their organizations. These findings demonstrate that most of the surveyed NSE listed firms had effective knowledge development and sharing practices. 
Table 1. Knowledge mobilization in the NSE listed firms.

\begin{tabular}{|c|c|c|c|c|c|c|c|}
\hline Statement & SD & $\mathrm{D}$ & $\mathrm{N}$ & $\mathrm{A}$ & SA & Mean & Std. Deviation \\
\hline $\begin{array}{l}\text { The organization has adequate equipment and resources to gather } \\
\text { knowledge }\end{array}$ & 2.8 & 5.6 & 11.1 & 36.1 & 44.4 & 4.14 & 1.018 \\
\hline The organization has a formal knowledge sharing policy & 2.8 & 2.8 & 8.3 & 36.1 & 50.0 & 4.28 & .944 \\
\hline $\begin{array}{l}\text { The organization has a collective information collection, sharing and } \\
\text { storage system }\end{array}$ & 2.8 & 8.3 & 11.1 & 38.9 & 38.9 & 4.03 & 1.055 \\
\hline $\begin{array}{l}\text { The organization has a strong culture of knowledge sharing among } \\
\text { employees }\end{array}$ & 8.3 & 11.1 & 11.1 & 36.1 & 33.3 & 3.75 & 1.273 \\
\hline $\begin{array}{l}\text { Decisions made by management are effectively communicated to } \\
\text { employees }\end{array}$ & 5.6 & 19.5 & 8.3 & 33.3 & 33.3 & 3.83 & 1.134 \\
\hline $\begin{array}{l}\text { Management ensures that new knowledge and information is } \\
\text { disseminated to all relevant organization employees }\end{array}$ & 2.8 & .0 & 25.0 & 44.4 & 27.8 & 3.94 & .893 \\
\hline Resources and time for learning is readily available to employees & 2.8 & 2.8 & 22.2 & 30.6 & 41.7 & 4.06 & 1.013 \\
\hline
\end{tabular}

The study results summarized in Table 1 revealed that $38.9 \%$ of the study participants strongly agreed with a similar percentage agreeing that their organizations had a collective information collection, sharing and storage system. Additionally, $36.1 \%$ of the respondents agreed with $33.3 \%$ strongly agreeing that their organizations had a strong culture of knowledge sharing among employees. Moreover, $33.3 \%$ of the study participants strongly agreed with a similar percentage agreeing that decisions made by management are effectively communicated to employees. These findings suggest that most of the organizations that participated in the study had effective systems and culture for knowledge creation, storage and sharing.

The study provided an open question in the questionnaire which was aimed at eliciting suggestions for improving knowledge mobilization in the organizations that participated in the study. The responses collected were analyzed using thematic summary analysis where the dominant themes were extracted. The key themes that were generated from the responses included organizational structure that supports knowledge creation and sharing, leadership that supports a knowledge culture, incentives and reward systems, recruiting based on knowledge capacity and having physical and technological infrastructure for knowledge creation, development and sharing. Besides, some respondents suggested employee training and development on knowledge, and selecting a technology that supports knowledge development and sharing.

\subsection{Financial Performance}

The dependent variable in the study was organizational performance. This section provides an analysis of the primary and secondary data collected on the variable. In the questionnaire, respondents were provided with two statements on organizational performance and were requested to rate the statements in the 
context of the nature of organizational performance that their organization enjoyed in the industry. The statements were on a scale of $1-5$ (Not at all NA, Small extent-SE, moderate extent-ME, great extent-GE and Very great extent-VGE). This section provides descriptive statistics from the analysis of the Likert scale responses. Means scores, percentages and standard deviations were derived from the analysis and study findings are presented in Table 2.

Study findings summarized in Table 2 reveal that $58.3 \%$ of the respondents indicated that their companies had experienced sustained improvement in market share in the past five years to great extent while $33.3 \%$ indicated that this was to a very great extent. Besides, $36.1 \%$ of the study respondents indicated that their companies had attained above average financial performance in the last five years to a very great extent while $33.3 \%$ indicated that this was experienced to a great extent. These findings imply that most of the NSE listed firms that participated in the study had experienced above average financial performance and improved market share in the past five years.

The study also collected secondary data on financial performance and market share for the latest financial year (2019/2020) for the 36 companies that participated in the study. Mean for the five years were computed and findings are presented in Table 3.

The study findings summarized in Table 3 reveal that the average financial performance of the selected NSE listed firms was $4.11 \%$. Besides, the average market share of the firms was $38.5 \%$. These findings indicate the firms that participated in the study experienced good organizational performance in terms of return on assets and market share. These findings support the findings from the questionnaire survey and hence the triangulation through the secondary data supported the results from the questionnaire survey.

\subsection{Regression of Organizational Performance against Knowledge Mobilization}

Regression analysis was conducted using knowledge mobilization against the dependent variable (organizational performance). The results of the regression model summary are presented in Table 4.

The study results summarized in Table 4 provide the correlation coefficient (r), coefficient of determination ( $\mathrm{r}$ squared), adjusted coefficient of determination (adjusted $r$ squared) and the standard error of estimate. The study findings indicate that the knowledge mobilization, innovation mobilization, and market mobilization had a high relationship with organizational performance $(r=.806)$. Besides, the study findings illustrate that knowledge mobilization explained 64.9\% of the variation in organizational performance in the NSE listed firms ( $\mathrm{r}$ squared $=.649$ ). This implies that $35.1 \%$ of the variation in organizational performance was unexplained by knowledge mobilization.

The study conducted an analysis of the regression variance to assess the significance of the regression model. The study findings are illustrated in Table 5. 
Table 2. Organizational performance of the firms listed in the NSE.

\begin{tabular}{llllllll}
\hline Statement & NA & SE & ME & GE & VGE & Mean & Std. Deviation \\
$\begin{array}{l}\text { The company has attained above } \\
\begin{array}{l}\text { average financial performance in } \\
\text { the last five years }\end{array}\end{array}$ & 5.6 & 2.8 & 22.2 & 33.3 & 36.1 & 3.92 & 1.105 \\
$\begin{array}{l}\text { The company has experienced } \\
\begin{array}{l}\text { sustained improvement in market } \\
\text { share in the past five years }\end{array}\end{array}$ & 2.8 & 5.6 & 58.3 & 33.3 & 4.22 & .681
\end{tabular}

Table 3. Financial performance of selected NSE listed firms.

\begin{tabular}{cc}
\hline Measure & Mean \\
\hline Financial Performance (ROA) & $4.11 \%$ \\
Market share & $38.5 \%$ \\
\hline
\end{tabular}

Table 4. Regression model summary.

\begin{tabular}{ccccc}
\hline Model & $\mathrm{R}$ & R Square & Adjusted R Square & Std. Error of the Estimate \\
\hline 1 & $.806^{\mathrm{a}}$ & .649 & .639 & .43447 \\
\hline
\end{tabular}

a. Predictors: (Constant), Knowledge Mobilization.

Table 5. Analysis of variance.

\begin{tabular}{ccccccc}
\hline \multicolumn{1}{c}{ Model } & Sum of Squares & df & Mean Square & F & Sig. \\
\hline & Regression & 11.863 & 1 & 11.863 & 62.849 & $.000^{\mathrm{b}}$ \\
1 & Residual & 6.418 & 34 & .189 & & \\
& Total & 18.281 & 35 & & & \\
& & &
\end{tabular}

a. Dependent Variable: Organizational Performance; b. Predictors: (Constant), Knowledge Mobilization.

The study results provided in Table 5 indicate that the model was statistically significant $(\mathrm{f}=62.849, p<.01)$. These findings suggest that there was sufficient evidence to conclude that the regression model was a good fit to the sample data set. Besides, the findings imply that the model has predictive importance and hence the independent has a significant influence on organizational performance of the NSE listed firms.

The study tested the significance of the independent variables (market mobilization, innovation mobilization, and knowledge mobilization) in the regression model. This was conducted through the $t$ test at $5 \%$ level of significance. The study results are summarized in Table 6 .

The study findings summarized in Table 6 reveal that knowledge mobilization had a positive and significant effect on organizational performance of firms listed in the NSE $(\beta=1.007 ; p<.05)$. The implication of these results is that a firm with a strong knowledge mobilization is expected to experience high organizational performance in comparison to its peers. Besides, the findings imply 
Table 6. Significance of knowledge mobilization in the regression model.

\begin{tabular}{|c|c|c|c|c|c|c|}
\hline & \multirow[t]{2}{*}{ Model } & \multicolumn{2}{|c|}{$\begin{array}{l}\text { Unstandardized } \\
\text { Coefficients }\end{array}$} & \multirow{2}{*}{$\begin{array}{c}\text { Standardized } \\
\text { Coefficients } \\
\text { Beta }\end{array}$} & \multirow[t]{2}{*}{$\mathrm{t}$} & \multirow[t]{2}{*}{ Sig. } \\
\hline & & B & Std. Error & & & \\
\hline \multirow{2}{*}{1} & (Constant) & .024 & .512 & & .047 & .962 \\
\hline & Knowledge Mobilization & 1.007 & .127 & .806 & 7.928 & .000 \\
\hline
\end{tabular}

a. Dependent Variable: Organizational Performance.

that a one-unit improvement in knowledge mobilization will improve organizational performance by 1.007 units. The study findings determined that knowledge mobilization had a strong positive linear relationship with organizational performance of the NSE listed firms $(r=806, p<.01)$. The results from regression analysis determined that knowledge mobilization had a positive and significant effect on organizational performance of firms listed in the NSE ( $\beta$ $=.297 ; p=.004)$. The findings suggest that a one-unit change in knowledge mobilization would result to a .439 direct change in organizational performance of the NSE listed firms. These findings support the RBT by Wernerfelt (1984) which hypothesizes that internal resources such as knowledge are critical in enabling the organization to attain its performance goals and objectives. Besides, Talaja, Miočević and Alfirević (2017) hypothesized that knowledge enables a firm to be more responsiveness to the changing competitive, market and customer dynamics. Knowledge therefore qualifies to be a strategic resource that enables the firm to create new products and improve existing offerings as dictated by the market changes. This facilitates the organization to continue in satisfying market expectations and positively affect its performance in terms of market share and profitability.

The findings from this study are supported by previous findings. For instance, the findings are supported by results from a study by Ismail, Rose, Uli and Abdullah (2017) who investigated the association between organizational performance and organizational learning and found that organizational knowledge was critical in influencing organizational performance. Other studies with comparable findings are Farrukh and Waheed (2015), Klindžić and Galetić (2015) and Shahram Gilaninia et al. (2013).

\section{Conclusion and Recommendations}

The study concludes that knowledge mobilization is indispensable for organizational performance of firms listed in the NSE. Improving the capacity of the organization to mobilize knowledge is associated with the capacity of the organization to improve its performance. The aspects of knowledge mobilization that are instrumental include having a formal knowledge sharing policy, having adequate equipment and resources to gather knowledge and sharing new knowledge and information with all relevant organization employees. Besides, having resources 
and time for learning, having a collective information collection, sharing and storage system, and a strong culture of knowledge sharing among employees are critical for knowledge mobilization.

After considering the conclusions made in the study, the following recommendations are provided. First, it is recommended that the NSE listed firms should adopt an organizational structure that supports knowledge creation and sharing, instil leadership that supports a knowledge culture, and provide incentives and reward systems. Additionally, the study recommends that organizations should have recruitment strategies that are based on knowledge capacity, engage on employee training and development on knowledge, and select a technology and systems that support knowledge development and sharing. Finally, organizations should also have physical and technological infrastructure for knowledge creation, development and sharing.

\section{Conflicts of Interest}

The authors declare no conflicts of interest regarding the publication of this paper.

\section{References}

Atoche, C. (2017). Capability Lifecycles: An Insight from the Innovation Capability Evolution in Emerging Economies. In Cladea's Annual Assembly (1-11). Tecnológico de Monterrey.

Babbie, E. R. (2011). The Practice of Social Research (12th ed.). Cengage.

Barney, J. B. (1991). Firm Capabilities and Sustained Competitive Advantage. Journal of Management, 17, 99-120. https://doi.org/10.1177/014920639101700108

Bowman, C., \& Ambrosini, V. (2013). How the Resource-Based View and the Dynamic Capability Views of the Firm Inform Corporate-Level Strategy. British Journal of Management, 24, 289-303. https://doi.org/10.1111/j.1467-8551.2003.00380.x

Davis, P. J., \& Simpson, E. (2017). Resource-Based Theory, Competition and Staff Differentiation in Africa: Leveraging Employees as a Source of Sustained Competitive Advantage. American Journal of Management, 17, 19-33.

Farrukh, M., \& Waheed, A. (2015). Learning Organization and Competitive Advantage: An Integrated Approach. Journal of Asian Business Strategy, 5, 73-79.

Gilaninia, S., Ganjinia, H., \& Karimi, K. (2013). The Relationship between Organizational Learning and Competitive Strategies and Its Impact on Performance of Business and Customer. Arabian Journal of Business and Management Review, 1, 54-60. https://doi.org/10.12816/0003625

Gillham, W. E. C. (2018). Developing a Questionnaire (5th ed.). Continuum.

Ismail, A. I., Rose, R. C., Uli, J., \& Abdullah, H. (2017). The Relationship between Organisational Resources, Capabilities, Systems and Competitive Advantage. Asian Academy of Management Journal, 17, 151-173.

Klindžić, M., \& Galetić, L. (2015). Organizational Learning as a Source of Competitive Advantage-Building a Context to Support Organizational Learning. Ekonomski pregled, 66, 106-113.

Kothari, C. R. (2004). Research Methodology: Methods and Techniques. New Age Inter- 
national.

Kumar, V., Jones, E., Venkatesan, R., \& Leone, R. P. (2011). Is Market Orientation a Source of Sustainable Competitive Advantage or Simply the Cost of Competing? Journal of Marketing, 75, 16-30. https://doi.org/10.1509/jmkg.75.1.16

Kurpius, S. E., \& Stafford, M. E. (2016). Testing and Measurement: A User-Friendly Guide (Kindle ed.). SAGE Publications.

Letangule, S., \& Letting, N. (2012). Effect of Performance Contract on Organizational Performance; the Case Study of Kenya's Ministry of Education. International Journal of Management and Business Studies, 11, 71-83.

Lin, C., \& Tsai, H. (2016). Achieving a Firm's Competitive Advantage through Dynamic Capability. Baltic Journal of Management, 11, 260-285. https://doi.org/10.1108/BJM-11-2015-0224

Malika, M. G., \& Kilika, J. (2014). Strategic Capabilities, Competitive Advantage and Firms Performance: A Research Agenda. International Journal of Science and Research, 7, 2594-2598.

NSE (2019a). About NSE. https://www.nse.co.ke/nse/about-nse.html

NSE (2019b). History of NSE. https://www.nse.co.ke/nse/history-of-nse.html

NSE (2019c). Listed Companies. https://www.nse.co.ke/listed-companies/list.html?limitstart $=0$

Okumu, A., Olweny, T., \& Muturi, W. (2021). Theoretical Review of Effect of Firm Specific Factors on Performance of Initial Public Offering Stocks at the Nairobi Securities Exchange in Kenya. Open Journal of Business and Management, 9, 327-352.

https://doi.org/10.4236/ojbm.2021.91018

Othman, R., Arshad, R., Aris, N. A., \& Arif, M. M. (2015). Organizational Resources and Sustained Organizational Performance of Cooperative Organizations in Malaysia. Procedia-Social and Behavioral Sciences, 170, 120-127.

https://doi.org/10.1016/j.sbspro.2015.01.021

Palladan, A. A., Abdulkadir, K. B., \& Wen, C. Y. (2016). The Effect of Strategic Leadership, Organization Innovativeness, Information Technology Capability on Effective Strategy Implementation: A Study of Tertiary Institutions in Nigeria. Arabian Journal of Business and Management Review, 6, 2-5.

Talaja, A., Miočević, D., \& Alfirević, N. (2017). Market Orientation, Organizational Performance and Business Performance: Exploring the Indirect Effects. Journal of Strategic Marketing, 24, 377-397.

Teece, D. J. (2016). Dynamic Capabilities and Entrepreneurial Management in Large Organizations: Toward a Theory of the (Entrepreneurial) Firm. European Economic Review, 86, 202-216. https://doi.org/10.1016/j.euroecorev.2015.11.006

Thomas, J. (2016). Doing Your Research Project (8th ed.). Open University Press.

Wernerfelt, B. (1984). A Resource-Based Theory of the Firm. Strategic Management Journal, 5, 171-180. https://doi.org/10.1002/smj.4250050207

Wheelen, T. H., \& Hunger, D. (2010). Strategic Management and Business Policy (12th ed.). Pearson Prentice Hall. 